\title{
MARK TUSHNET E AS ASSIM CHAMADAS DIMENSÕES ("GERAÇÕES") DOS DiREITOS HUMANOS E FUNDAMENTAIS: BREVES NOTAS
}

INGO WOLFGANG SARLET ${ }^{\dagger}$

\section{UM DOSSIÊ SOBRE TAXONOMIA DAS GERAÇÕES DE DIREITOS}

Palavras-Chave: Direitos Fundamentais; Constitucionalismo; Gerações de Direitos.

KEYWORDS: Fundamental Rights; Constitutionalism; Generations of Rights.

\footnotetext{
† Doutor e Pós-Doutor em Direito pela Ludwig-Maximilians-Universität München, Alemanha. Professor Titular da Pontifícia Universidade Católica do Rio Grande do Sul. Desembargador do Tribunal de Justiça do Estado do Rio Grande do Sul.
} 
SUMÁRIO:

I. CONSIDERAÇÕES PRELIMINARES.......................................................500

II. AS TRÊS PRIMEIRAS DIMENSÕES DE DIREITOS: LIBERDADE, IGUALDADE E FRATERNIDADE? ...................................502

III. EVENTUAIS TENSÕES E MESMO CONFLITO ENTRE AS DIVERSAS DIMENSÕES DE DIREITOS E ALGUMAS CONSIDERAÇÕES DE CARÁTER CRÍTICO-REFLEXIVO .................................................508

IV. REFERÊNCIAS........................................................................................514

\section{TABLE OF CONTENTS:}

I. PRELIMINARY CONSIDERATIONS ................................................500

II. THE FIRST THREE DIMENSIONS OF RIGHTS:: LIBERTY, EQUALITY AND FRATERNITY? ..

III. EVENTUAL TENSIONS AND SAME CONFLICTS BETWEEN VARIOUS DIMENSIONS OF RIGHTS AND SOME CONSIDERATIONS OF CRITICAL-REFLEXIVE CHARACTER..........................................508

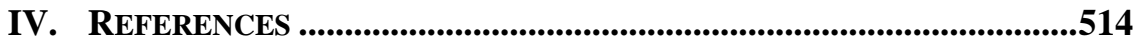




\section{CONSIDERAÇÕES PRELIMINARES}

Desde o seu reconhecimento nas primeiras constituições, os direitos fundamentais passaram por diversas transformações, tanto no que diz com o seu conteúdo, quanto no que concerne à sua titularidade, eficácia e níveis de proteção. O mesmo, ainda que em escala diversa, pode ser dito quanto à evolução ocorrida na seara do direito internacional dos direitos humanos. Costuma-se, nesse contexto marcado por uma autêntica mutação histórica experimentada pelos direitos humanos e fundamentais, ${ }^{1}$ falar da existência do que Karel Vasak, quando de sua aula inaugural no Instituto Internacional de Direitos Humanos de Estrasburgo, em 1979, optou por designar de gerações de direitos humanos (e fundamentais), inspirando-se na famosa tríade da Revolução Francesa: liberdade, igualdade e fraternidade, à qual corresponderiam três gerações de direitos humanos e fundamentais. A partir de então não faltaram defensores da existência, ao longo do tempo, de novas gerações de direitos, agregando uma quarta, mas até mesmo uma quinta e sexta gerações.

Por outro lado, também não faltam análises críticas a respeito das assim chamadas gerações de direitos, a começar pelo aspecto terminológico, sendo de realçar (inclusive por ser também a posição adotada) a objeção de que melhor seria utilizar a expressão dimensões de direitos, visto que o reconhecimento progressivo de novos direitos humanos e fundamentais tem o caráter de um processo cumulativo, de complementaridade, e não de alternância, de tal sorte que o uso da expressão "gerações" poderia ensejar a falsa impressão da substituição gradativa de uma geração por outra ${ }^{2}$.

Nesse mesmo contexto, aludiu-se, de forma notadamente irônica, ao que se chama de "fantasia das chamadas gerações de direitos", que, além da imprecisão terminológica já consignada, conduz ao entendimento equivocado de que os direitos fundamentais se substituem ao longo do tempo, não se encontrando em permanente processo de expansão,

${ }^{1}$ Nesse sentido, a lição de PÉREZ LUÑO, Antonio-Enrique, Las generaciones de derechos Humanos. Revista del Centro de Estudios Constitucionales, n. 10, 1991, p. 205, para quem o aparecimento de sucessivas dimensões de direitos fundamentais foi determinado justamente pela mutação histórica destes direitos.

${ }^{2}$ Cf., por todos, BONAVIDES, Paulo. Curso de Direito Constitucional. $7^{\mathfrak{a}}$ ed. São Paulo, SP: Malheiros, 1999, p. 525 (note-se que o autor, nas edições posteriores, manteve tal crítica, mas também sugere a ampliação do número de dimensões para uma quarta e quinta). 
cumulação e fortalecimento. ${ }^{3}$ Ressalte-se, todavia, que a discordância não se encontra restrita ao domínio da terminologia, mas também diz respeito ao número de dimensões de direitos e o conteúdo de cada dimensão, assim como a relação entre as diversas dimensões.

Nessa senda, importa sublinhar que o processo de reconhecimento de direitos humanos e fundamentais nos catálogos constitucionais e na seara do Direito Internacional, revela que os direitos reconhecidos e garantidos ao longo do tempo consistem em múltiplas e diferenciadas posições jurídicas, cujo conteúdo é tão variável quanto as transformações ocorridas na realidade social, política, cultural e econômica ao longo dos tempos. ${ }^{4}$ Assim sendo, adeptos da teoria dimensional dos direitos fundamentais não apontam apenas para o caráter cumulativo do processo evolutivo e para a natureza complementar de todos os direitos fundamentais, mas afirmam, para além disso, sua unidade e indivisibilidade no contexto do direito constitucional interno e, de modo especial, na esfera do moderno "Direito Internacional dos Direitos Humanos". ${ }^{5}$

É precisamente nesse contexto que se situa o atual e instigante texto de Mark Tushnet (Notes on Some Aspects of the Taxonomy of "Generations" of Rights $^{6}$ ) objeto do presente comentário. No texto, entre outros pontos, Tushnet, além de traçar uma breve definição do que considera ser o conteúdo das três gerações (aqui usando o terminus privilegiado pelo autor) convencionais de direitos, discute a existência de uma relação de compatibilidade entre as três gerações e discute os argumentos em torno

${ }^{3}$ Cf. TRINDADE, Antônio Augusto Cançado. Tratado de Direito Internacional dos Direitos Humanos. Vol. I. Porto Alegre, RS: S.A. Fabris, 1997, p. 24-5.

${ }^{4}$ Aqui vale referir, dentre outros, a posição de WEIS, Carlos. Direitos Humanos Contemporâneos. São Paulo, SP: Malheiros, 1999, p. 37 e ss., que, criticando a concepção tradicional das "gerações" de direitos humanos, ainda aponta a circunstância de que as classificações tradicionais - baseadas no critério da evolução histórica - além de gerarem confusões de cunho conceitual, pecam por não zelarem pela correspondência entre as assim designadas gerações de direitos humanos e o processo histórico de nascimento e desenvolvimento destes direitos, razão pela qual propõe um outro critério classificatório, sintonizado com a positivação no plano internacional, de tal sorte que se poderia falar de direitos liberais (civis e políticos) e direitos sociais, econômicos e culturais, adotando-se a terminologia "direitos globais" para aqueles direitos que a doutrina costuma enquadrar na terceira geração. ${ }^{5}$ Cf., por todos, TRINDADE, Antônio Augusto Cançado. Tratado de Direito Internacional dos Direitos Humanos. Vol. I. Porto Alegre, RS: S.A. Fabris, 1997, p. 25. 6 TUSHNET, Mark. Notes on Some Aspects of the Taxonomy of "Generations" of Rights. Revista Estudos Institucionais, Vol. 2, 2, 2016.

2 JOURNAL OF INSTITUTIONAL STUDIES 2 (2016) 
de uma contradição insuperável entre aquelas, inclusive de modo a sugerir que o reconhecimento e efetivação de direitos da segunda e mesmo terceira geração pode implicar a violação ou redução do papel dos direitos (civis e políticos) da assim chamada primeira dimensão. E sobre tais considerações, aqui apenas rapidamente esboçadas, que será apoiado o nosso breve comentário. Além disso, convém seja destacado - para espancar qualquer incompreensão - que, diferentemente da terminologia adotada por Tushnet, seguiremos utilizando o termo dimensões, inclusive para mantermos a coerência com a posição que perfilhamos por tanto tempo.

\section{AS TRÊS PRIMEIRAS DIMENSÕES DE DIREITOS: LIBERDADE, IGUALDADE E FRATERNIDADE?}

Quanto ao número de dimensões de direitos e o seu conteúdo, é possível extrair do texto de Tushnet a sua substancial adesão à proposição clássica de Karel Vasak, ou seja, de que existem apenas três, representadas, respectivamente, pelos direitos de matriz liberalburguesa, as liberdades e garantias civis e políticas, a segunda dimensão representada pelos direitos econômicos e sociais de caráter eminentemente positivo (prestacional) e voltados à garantia de determinados padrões de segurança social e igualdade e material a exigir determinados níveis de intervenção estatal no domínio do mercado e da economia, bem como uma terceira dimensão, composta - segundo o ator - por direitos culturais e de linguagem e mais recentemente os direitos ambientais.

Já a partir de tais considerações, que, em termos gerais coincidem com o nosso entendimento pessoal (ao menos quanto ao número de dimensões e em geral também quanto ao seu conteúdo) é possível anotar que se cuida de posição controversa, pois são diversos os autores que reconhecem a existência de dimensões adicionais, variando entre quatro, cinco e até mesmo seis, com conteúdo igualmente variável. Da mesma forma há os que divergem, ao menos parcialmente, no que diz com o conteúdo de cada dimensão, inclusive - e em especial - da assim chamada terceira dimensão, sem prejuízo de eventuais implicações de tais entendimentos em relação ao problema da natureza e em especial exigibilidade de tais direitos, bem como no concernente às relações mais ou menos convergentes e complementares entre as diferentes gerações, aspectos também tematizados por Tushnet, mas que serão objeto de apreciação no próximo segmento. 
Antes de focarmos as questões atinentes ao número de dimensões, vale sublinhar que em maior ou menor medida existem pontos de convergência quanto ao conteúdo das diferentes dimensões, como bem dá conta o caso dos direitos da segunda dimensão, visto que tais direitos não englobam apenas direitos de cunho positivo (direitos a prestações sociais), mas também abarcam as assim denominadas "liberdades sociais" (José Carlos Vieira de Andrade), tal como atestam os exemplos da liberdade sindical, do direito de greve, bem como o reconhecimento de direitos fundamentais aos trabalhadores, tais como o direito a férias e ao repouso semanal remunerado, a garantia de um salário mínimo, a limitação da jornada de trabalho, apenas para citar alguns dos mais representativos. Assim, ao contrário do que parece fazer crer a visão dominante, a segunda dimensão dos direitos fundamentais não pode ser caracterizada como limitada aos direitos de caráter positivo (direitos a prestações), ainda que se possa afirmar que a "face positiva" dos direitos sociais seja o marco distintivo dessa nova fase na evolução dos direitos fundamentais ${ }^{7}$.

Além disso, as referidas "liberdades sociais", correspondem, em virtude de sua estrutura e âmbito de proteção, a posições jurídicas que buscam assegurar a não intervenção do Estado e mesmo de atores privados em determinados domínios, representando, ademais, liberdades negativas e positivas (direito de fazer ou não a greve, de formar e/ou integrar, ou não, uma associação sindical, etc.), sua inserção, a depender do critério adotado, poderia ocorrer até mesmo na esfera dos direitos da primeira dimensão, ao menos na categoria de direitos análogos, o que, de certa forma, corresponde ao modelo da Constituição da República Portuguesa desde a sua primeira revisão. Sua inserção na assim chamada segunda dimensão, por sua vez, se justifica pelo fato de que não apenas se cuida da ampliação da fruição das liberdades para um grupo maior de pessoas, mas especialmente pela atribuição de liberdades instrumentais para a conquista de outros direitos, designadamente do direito de acesso e participação em prestações de justiça social, no sentido de liberdades para a igualdade material. De qualquer sorte, o exemplo das liberdades sociais bem atesta o quanto é questionável, do ponto de vista do rigor científico, a classificação dos direitos fundamentais em dimensões fundadas na liberdade e igualdade.

Quanto aos direitos fundamentais da terceira dimensão, também denominados de direitos de fraternidade ou de solidariedade, os mesmos

${ }^{7}$ Cf. SARLET, Ingo Wolfgang. A Eficácia dos Direitos Fundamentais: Uma Teoria

Geral dos Direitos Fundamentais na Perspectiva Constitucional. 10 ed. Porto Alegre, RS: Livraria do Advogado, 2009.

2 JOURNAL OF INSTITUTIONAL STUDIES 2 (2016) 
trazem como nota distintiva o fato de se desprenderem, em princípio, da figura do homem-indivíduo como seu titular, destinando-se à proteção de grupos humanos (família, povo, nação), e caracterizando-se, consequentemente, como direitos de titularidade coletiva ou difusa. ${ }^{8}$ Para outros, os direitos da terceira dimensão têm por destinatário precípuo "o gênero humano mesmo, num momento expressivo de sua afirmação como valor supremo em termos de existencialidade concreta". ${ }^{9}$ Dentre os direitos fundamentais da terceira dimensão consensualmente mais citados, cumpre referir os direitos à paz, à autodeterminação dos povos, ao desenvolvimento, ao meio ambiente e qualidade de vida, bem como o direito à conservação e utilização do patrimônio histórico e cultural e o direito de comunicação, ${ }^{10}$ o que, como já adiantado, em termos substanciais corresponde à posição de Tushnet.

A nota distintiva desses direitos da terceira dimensão reside, segundo a perspectiva ora adotada, basicamente na sua titularidade coletiva, muitas vezes indefinida e indeterminável, o que se revela, a título de exemplo, especialmente no direito ao meio ambiente e qualidade de vida, o qual, em que pese ficar preservada sua dimensão individual, reclama novas técnicas de garantia e proteção. A atribuição da titularidade de direitos fundamentais ao próprio Estado e à Nação (direitos à autodeterminação, paz e desenvolvimento) tem suscitado - como é o caso de Norberto Bobbio - sérias dúvidas no que concerne à própria qualificação de grande parte dessas reivindicações como autênticos direitos fundamentais. ${ }^{11}$ Compreende-se, portanto, porque os direitos da terceira dimensão são denominados usualmente como direitos de solidariedade ou fraternidade, de modo especial em face de sua implicação universal ou, no mínimo, transindividual, e por exigirem esforços e responsabilidades em escala até mesmo mundial para sua efetivação.

Mas - é preciso sublinhar! - nem para todos os autores dedicados ao

${ }^{8}$ Cf. LAFER, Celso. A Reconstrução dos Direitos Humanos: Um Diálogo com o

Pensamento de Hannah Arendt. São Paulo, SP: Companhia das Letras, 1988, p. 131.

${ }^{9}$ Cf. BONAVIDES, Paulo. Curso de Direito Constitucional. $7^{a}$ ed. São Paulo, SP:

Malheiros, 1999, p. 523.

${ }^{10}$ Cf., dentre outros, BONAVIDES, Paulo. Curso de Direito Constitucional. $7^{\mathrm{a}}$ ed. São

Paulo, SP: Malheiros, 1999, p. 523.

${ }^{11}$ Neste sentido, v. RIEDEL, Eibe. Menschenrechte der dritten Dimension. Europäische Grundrechte Zeitschrift, Vol. 16, 1/2, 1989, p. 17 e ss. Esta dúvida também é suscitada por BOBBIO, Norberto. A Era dos Direitos. 8 ed. Trad. Carlos Nelson Coutinho. Rio de Janeiro, RJ: Ed. Campus, 1992, p. 9-10. 
tema os direitos da terceira dimensão se identificam (pelo menos como critério determinante da classificação) com a noção de solidariedade/fraternidade e com a circunstância de se tratar de direitos de caráter transindividual, inclusive titularizados por Estados e povos. Nessa perspectiva vale referir o magistério de Pérez Luño, para quem os direitos fundamentais da terceira dimensão podem ser considerados uma resposta ao fenômeno denominado de "poluição das liberdades", que caracteriza o processo de erosão e degradação sofrido pelos direitos e liberdades fundamentais, principalmente em face do uso de novas tecnologias. Aqui - e para o autor referido - assumem especial relevância o direito ao meio ambiente e à qualidade de vida (que, contudo, integra a terceira dimensão já em virtude de sua titularidade transindividual), bem como o direito de informática (ou liberdade de informática), cujo reconhecimento é postulado justamente em virtude do controle cada vez maior sobre a liberdade e intimidade individual mediante bancos de dados pessoais, meios de comunicação etc., ${ }^{12}$ mas que - em virtude de sua vinculação com os direitos de liberdade (inclusive de expressão e comunicação) e as garantias da intimidade e privacidade suscita dúvidas no que tange ao seu enquadramento na terceira dimensão dos direitos fundamentais. Ainda nesse contexto, costumam ser feitas referências às garantias contra manipulações genéticas, ao direito de morrer com dignidade, igualmente considerados, por parte da doutrina, de direitos da terceira dimensão, ressaltando-se que, para alguns, já se cuida de direitos de uma quarta dimensão ${ }^{13}$.

De qualquer sorte, especialmente em relação a tais direitos relacionados aos riscos e impacto da tecnologia na sociedade da informação e do conhecimento - valendo-nos aqui da terminologia usual - verifica-se, contudo, que, a despeito de estarem ainda em processo de reivindicação e desenvolvimento os mesmos correspondem, em verdade, a facetas novas deduzidas do princípio da dignidade da pessoa humana, encontrando-se intimamente vinculados à ideia da liberdade-autonomia e da proteção da vida e outros bens fundamentais (igualdade,

${ }_{12}$ Cf. PÉREZ LUÑO, Antonio-Enrique, Las generaciones de derechos Humanos.

Revista del Centro de Estudios Constitucionales, n. 10, 1991, p. 206 e ss.

${ }^{13}$ Cf., entre outros, WOLKMER, Antônio Carlos. Introdução aos fundamentos de uma teoria geral dos "novos" direitos. In: Antônio Carlos Wolkmer \& José Rubens Morato Leite (Orgs.). Os “Novos" Direitos no Brasil: Natureza e Perspectivas. Uma visão básica das novas conflituosidades jurídicas. $2^{\underline{a}}$ ed. São Paulo, SP: Editora Saraiva, 2003, p. 27 e ss.; e FACHIN, Zulmar; SILVA, Deise Marcelino da. Acesso à água potável: Direito fundamental de sexta dimensão. Campinas, SP: Brazil Millennium, 2011, p. 71 e ss.

2 JOURNAL OF INSTITUTIONAL STUDIES 2 (2016) 
privacidade, integridade corporal e identidade pessoal) contra ingerências por parte do Estado e dos particulares. Assim, cuida-se, no mais das vezes, da reivindicação de novas dimensões das liberdades fundamentais, cujo reconhecimento se impõe em face dos impactos da sociedade industrial e técnica, designadamente na assim chamada sociedade da informação e do conhecimento, que marca a transição do Século XX, quando tais questões já vinham ganhando relevo (aqui considerada a perspectiva dos direitos humanos e fundamentais) especialmente a contar dos anos 1970, para o Século XXI.

Na sua essência e pela sua estrutura jurídica de direitos de cunho excludente e negativo, atuando como direitos de caráter preponderantemente defensivo, tais direitos (evidentemente não os que se caracterizam pela titularidade essencialmente transindividual) poderiam - e, de resto, deveriam - ser enquadrados na categoria dos direitos da primeira dimensão e mesmo segunda dimensão, evidenciando assim a permanente atualidade dos direitos de liberdade e igualdade, ainda que com nova roupagem e adaptados às exigências do homem contemporâneo.

Ainda assim, como já referido - e limitando-nos aqui a contribuições de autores brasileiros - há quem sugira a existência de uma quarta ${ }^{14}$, mas também de uma quinta ${ }^{15} \mathrm{e}$ até mesmo de uma sexta dimensão em matéria de direitos fundamentais ${ }^{16}$. Quanto ao seu conteúdo, a despeito de importantes variações na literatura, em termos gerais a quarta dimensão seria integrada pelo direito à democracia direta ${ }^{17}$, bem como pelos direitos à informação e ao pluralismo. ${ }^{18}$ No que diz com uma quinta

${ }^{14}$ Cf. BONAVIDES, Paulo. Curso de Direito Constitucional. $7^{\mathrm{a}}$ ed. São Paulo, SP:

Malheiros, 1999, p. 524 e ss.

${ }_{15}$ Cf. OLIVEIRA JÚNIOR, José Alcebíades de. Teoria Jurídica e Novos Direitos. Rio de Janeiro, RJ: Lumen Juris, 2000, p. 97 e ss.

${ }^{16}$ Cf. FACHIN, Zulmar; SILVA, Deise Marcelino da. Acesso à água potável: Direito fundamental de sexta dimensão. Campinas, SP: Brazil Millennium, 2011, p. 74 e ss., aderindo às concepções que reconhecem a existência de uma quarta e quinta dimensão.

${ }^{17}$ Cf. BONAVIDES, Paulo. Teoria Constitucional da Democracia Participativa: por um direito constitucional de luta e resistência, por uma nova hermenêutica, por uma repolitização da legitimidade. São Paulo, SP: Malheiros, 2001, em obra que reúne importantes estudos sobre o tema.

${ }^{18}$ Cf. BONAVIDES, Paulo. Curso de Direito Constitucional. $7^{\mathrm{a}}$ ed. São Paulo, SP: Malheiros, 1999, p. 524-6, apresentando e analisando os direitos da quarta dimensão em capítulo próprio. É de se ressaltar que, ao menos parcial e embrionariamente, 
dimensão, esta diz respeito ao direito à paz (que, na acepção original de Karel Vasak, estaria já situado na terceira dimensão), que, como aponta Paulo Bonavides, teria sede, no caso brasileiro, no artigo $4^{\circ}$, inciso VI, da Constituição Federal de 1988, e que poderia até mesmo ser invocado na esfera das relações internacionais, mas também em decisões de tribunais nacionais, como ocorreu no caso de processo apreciado pela Sala Constitucional da Suprema Corte de Justiça da Costa Rica. ${ }^{19}$

Mas também quanto ao conteúdo de uma quinta dimensão dos direitos humanos e fundamentais não se verifica consenso. Ao passo que para José Alcebíades de Oliveira Júnior e Antonio Wolkmer tal dimensão trata dos direitos vinculados aos desafios da sociedade tecnológica e da informação, do ciberespaço, da Internet e da realidade virtual em geral ${ }^{20}$, para José Adércio Sampaio a quinta dimensão abarca o dever de cuidado, amor e respeito para com todas as formas de vida, bem como direitos de defesa contra as formas de dominação biofísica geradores de toda sorte de preconceitos ${ }^{21}$.

Outrossim, existe inclusive, fixando-nos na literatura brasileira, quem defenda a existência de uma sexta dimensão, representada pelo direito humano e fundamental de acesso à água potável, como deflui da proposta de Zulmar Fachin e Deise Marcelino da Silva ${ }^{22}$, baseando-se especialmente na gradual consagração de tal direito no cenário do direito internacional dos direitos humanos e do direito constitucional comparado, ademais da relevância inequívoca da água potável para a

alguns desses direitos, notadamente os direitos à democracia, ao pluralismo e à informação, se encontram consagrados em na Constituição Federal de 1988, de modo especial no Preâmbulo e no Título dos Princípios Fundamentais, salientando-se, todavia, que a democracia erigida à condição de princípio fundamental pelo Constituinte de 1988 é a representativa, com alguns ingredientes, ainda que tímidos, de participação direta.

${ }^{19}$ Cf. BONAVIDES, Paulo. A quinta geração de direitos fundamentais. Direitos Fundamentais \& Justiça, Ano 2, nº 3, 2008, p. 82 e ss.

${ }^{20}$ Cf. OLIVEIRA JÚNIOR, José Alcebíades de. Teoria Jurídica e Novos Direitos. Rio de Janeiro, RJ: Lumen Juris, 2000, p. 100; WOLKMER, Antônio Carlos. Introdução aos fundamentos de uma teoria geral dos "novos" direitos. In: Antônio Carlos Wolkmer \& José Rubens Morato Leite (Orgs.). Os "Novos" Direitos no Brasil: Natureza e

Perspectivas. Uma visão básica das novas conflituosidades jurídicas. $2^{\underline{a}}$ ed. São Paulo, SP: Editora Saraiva, 2003, p. 29 e ss.

${ }^{21}$ Cf. SAMPAIO, José Adércio Leite. Direitos Fundamentais: Retórica e Historicidade. Belo Horizonte, MG: Del Rey, 2004, p. 29,

${ }^{22}$ Cf. FACHIN, Zulmar; SILVA, Deise Marcelino da. Acesso à água potável: Direito fundamental de sexta dimensão. Campinas, SP: Brazil Millennium, 2011, p. 74 e ss. 
vida, a saúde e mesmo o desenvolvimento humano.

O que se percebe, todavia, é tanto a ausência de consenso sobre o conteúdo da quarta, quinta e sexta dimensão dos direitos, quanto a circunstância de que se trata, em todos os casos e mesmo em todas as propostas aqui sumariamente elencadas, de direitos que já poderiam ser reconduzidos - isso partindo-se do pressuposto por si só controverso de que faz algum sentido falar-se em dimensões dos direitos humanos e fundamentais na acepção ora apresentada e discutida! - de algum modo às três primeiras dimensões de direitos, das quais também fala Tushnet no seu texto, ainda que sem referência específica aos direitos ligados às novas tecnologias, em especial na era digital e no campo da biotecnologia, bem como aos direitos à paz, democracia e pluralismo.

Ademais disso - e convém frisar esse ponto para preservar o autor que não é possível, salvo melhor juízo, inferir do ensaio ora comentado, qual efetivamente é o entendimento do autor, em toda a sua extensão, sobre a inclusão, ou não, de outros direitos nas dimensões por ele apontadas, muito embora - e isso desde logo arriscamos afirmar! - nisso não residam, na sua essência, os problemas ligados aos diversos tipos de conflitos e tensões entre os direitos das diversas gerações (em especial as três mais convencionais) identificados e analisados por Tushnet, do que, aliás, nos ocuparemos na próxima e última parte.

\section{EVENTUAIS TENSÕES E MESMO CONFLITO ENTRE AS DIVERSAS DIMENSÕES DE DIREITOS E ALGUMAS CONSIDERAÇÕES DE CARÁTER CRÍTICO-REFLEXIVO}

Ainda que se deva concordar com o argumento de que a divisibilidade dos direitos em dimensões (ou gerações), assim como as demais tipologias elaboradas relativamente aos direitos fundamentais não logra, por si só, explicar de modo satisfatório toda a complexidade do processo de formação histórica e social dos direitos, ${ }^{23}$ não hesitamos em consignar que o breve olhar lançado sobre as diversas dimensões dos

${ }^{23}$ Cf. desenvolvido por BRANDÃO, Paulo de Tarso. Ações Constitucionais: novos direitos e acesso à justiça. Florianópolis, SC: Habitus, 2001, p. 123 e ss. Embora referindo já cinco "gerações" de direitos, v. as críticas direcionadas especialmente em relação às três últimas "gerações" por SAMPAIO, José Adércio Leite. Direitos

Fundamentais: Retórica e Historicidade. Belo Horizonte, MG: Del Rey, 2004, p. 302 e ss., além das objeções em relação à própria classificação geracional (p. 308 e ss.). 
direitos fundamentais nos revela que o seu processo de reconhecimento é de cunho essencialmente dinâmico e dialético, marcado por avanços, retrocessos e contradições, ${ }^{24}$ ressaltando, dentre outros aspectos, a dimensão histórica e relativa dos direitos fundamentais, que se desprenderam - no mínimo, em grande parte - de sua concepção inicial de inspiração jusnaturalista. Importante é, neste particular, a constatação - em linhas gerais compartilhada por Tushnet (que refere a associação dos direitos das três dimensões a mobilizações políticas de grupos sociais) -, de que os direitos fundamentais são, acima de tudo, fruto de reivindicações concretas, geradas por situações de injustiça e/ou de agressão a bens fundamentais e elementares do ser humano. ${ }^{25}$

Ainda nesse contexto, aponta-se para a circunstância de que, na esfera do direito constitucional interno - e mesmo na esfera do direito internacional - tal evolução se processa habitualmente não tanto (mas também e de modo crescente) por meio da positivação desses "novos" direitos fundamentais no texto das Constituições, mas principalmente em nível de uma transmutação hermenêutica e da criação jurisprudencial, no sentido do reconhecimento de novos conteúdos e funções de alguns direitos já tradicionais. ${ }^{26}$

De qualquer sorte, deixando de lado aqui um aprofundamento (aqui inviável) de o problema de uma banalização e mesmo hipertrofia dos direitos humanos e fundamentais, basta sinalar que o número maior ou menor de dimensões de direitos fundamentais não assume, por si só, maior relevância teórica e prática, servindo, contudo, de recurso didático para ilustrar que se trata de um processo cumulativo e aberto, a desnudar o caráter essencialmente histórico-relativo dos direitos, não se pode desprezar - a exemplo do que justamente propõe Tushnet - a discussão em torno de tensões e mesmo conflitos entre os direitos das diferentes gerações, que não apenas são encontrados na esfera doutrinária, mas também encontram amparo em diferenciações ligadas ao texto das diferentes constituições e mesmo na perspectiva da aplicação e interpretação dos direitos pelos Tribunais, aqui apenas para citar alguns dos problemas.

${ }^{24}$ Nesse sentido, PÉREZ LUÑO, Antonio-Enrique, Las generaciones de derechos Humanos. Revista del Centro de Estudios Constitucionales, n. 10, 1991, p. 217.

${ }^{25}$ Cf., dentre outros, RIEDEL, Eibe. Menschenrechte der dritten Dimension.

Europäische Grundrechte Zeitschrift, Vol. 16, 1/2, 1989, p. 10.

${ }^{26}$ Cf., dentre outros, a lição de DENNINGER, Erhard. Der Gebändigte Leviathan.

Baden-Baden: Nomos Verlagsgesellschaft, 1990, p. 225-6, referindo-se, especificamente, à redescoberta dos direitos à segurança, meio ambiente sadio e equilibrado, proteção da liberdade em face dos riscos e agressões gerados pela tecnologia etc. 
Numa primeira linha argumentativa colacionada por Tushnet, situam-se as críticas daqueles que já na aurora do constitucionalismo social (como foi o caso de Carl Schmitt) e mesmo atualmente sustentam que a realização dos direitos da segunda e mesmo terceira dimensão (esta, à evidência, mais recentemente) implica violações dos direitos da primeira (em face de excessos em termos de intervenção estatal no mercado e na autonomia privada e propriedade, por exemplo) ou então torna cogente uma nova compreensão e configuração desses de modo a amoldá-los às exigências daqueles. Os exemplos que poderiam ser citados são múltiplos e Tushnet arrola alguns ilustrativos, como o caso da regulação do discurso do ódio, que levaria, segundo alguns, a uma violação da liberdade de expressão, ao passo que para outros tal regulação aperfeiçoa, redefine e garante o direito de igualdade ou o conflito entre direitos culturais da terceira dimensão e direitos da primeira dimensão.

Tais conflitos, como anota Tushnet, podem ser resolvidos, na perspectiva da doutrina de Robert Alexy, na medida em que os direitos das diferentes dimensões são sujeitos a um processo de otimização, no sentido de uma acomodação mútua, ou mesmo, tal como sugere Konrad Hesse (o que aqui tomamos a liberdade de agregar), impõe seja estabelecida uma "concordância prática", sem que se parta da primazia de uns sobre os outros, mas sim, do pressuposto de sua igual dignidade constitucional.

Além disso, ainda de acordo com Tushnet, imperativo identificar quais os direitos a serem otimizados, pois tal operação apenas será legítima em se tratando de direitos fundamentais reconhecidos como tais em determinada ordem constitucional, diferentemente dos casos em que os direitos de segunda e/ou terceira dimensão, ou mesmo alguns deles, não foram contemplados no texto constitucional, situação na qual o que se verifica é uma contraposição entre direitos e meros interesses, o que apenas não seria o caso quando operada (em geral por obra da jurisprudência constitucional) a inclusão de direitos associados à segunda e/ou terceira dimensão no âmbito de proteção de direitos da primeira, como é o caso, por exemplo, do direito à saúde em relação ao direito à vida ou mesmo o reconhecimento de um direito a um mínimo existencial como exigência da dignidade humana e de um direito ao livre desenvolvimento da personalidade, dentre outros.

Para Tushnet, a acomodação de todos os direitos numa só categoria poderia levar a uma diluição das reais diferenças entre os direitos das três dimensões, ao passo que a técnica da inclusão de direitos de segunda e terceira dimensão no espectro protetivo de direitos da primeira dimensão parece resolver conflitos ou tensões mediante recurso a um truque 
conceitual (a definitional trick), o que se revela compreensível precisamente em casos como o da Índia e da Alemanha, onde as Cortes Constitucionais utilizaram tal expediente para contornar e compensar a ausência de direitos sociais, econômicos e culturais no texto constitucional.

Partindo da premissa de que os conflitos e tensões entre direitos das diferentes dimensões são reais e qualitativamente distintos e mais intensos do que os conflitos entre direitos da primeira dimensão, Tushnet - reconhecendo a possibilidade de uma otimização entre direitos de dimensões distintas - sugere duas técnicas para resolver e, portanto, superar tais conflitos e estabelecer uma acomodação entre os direitos, a primeira de natureza institucional, a segunda de caráter doutrinário. No primeiro caso, o argumento é o de que formas fracas e dialógicas de controle judicial são particularmente adequadas para manejar a realização dos direitos da segunda dimensão, demandando, contudo, uma interação entre o Poder Legislativo e os Tribunais Constitucionais. Do ponto de vista doutrinário, a técnica da proporcionalidade deve ser privilegiada, que não mais deve ser limitada à solução de conflitos entre direitos da primeira dimensão, mas sim, ampliada para abarcar também conflitos desses direitos com os das dimensões subsequentes, de tal sorte que tais direitos não mais poderiam ser tidos como meros interesses de peso menor que o atribuído aos direitos da primeira dimensão.

Por outro lado, adverte Tushnet, a aplicação do teste da proporcionalidade, que já se revela por vezes problemático quando aplicado aos direitos da primeira dimensão, careceria de maior refinamento e elaboração quando manejado para solucionar conflitos entre direitos de dimensões distintas, particularmente entre direitos da primeira e segunda dimensão, formulados de modo em geral mais indeterminado e associados a políticas públicas e ao seu financiamento, bem como os problemas daí decorrentes ou correlatos.

Em caráter conclusivo, Tushnet sugere que os direitos de segunda e terceira dimensão contribuem para aperfeiçoar e ampliar a noção de direitos humanos em termos gerais, em especial, contudo, operando de modo a complementar os direitos da primeira dimensão, assim como a sua realização daqueles requer uma revisão da compreensão de aspectos específicos relativos aos últimos, ou seja, os direitos da primeira dimensão.

À vista do exposto, necessárias algumas notas adicionais, até mesmo no sentido de uma avaliação crítica da linha de pensamento trilhada por Tushnet, ainda que não exaustivamente inventariada.

Uma primeira observação diz respeito ao fato de que na avaliação de Tushnet não foi - ao menos assim o parece - devidamente considerada e 
refletida a hipótese de conflitos entre direitos de diferentes dimensões, quando os direitos das três dimensões (e mesmo outras, para quem assim preferir) tenham sido objeto de amplo reconhecimento, inclusive com a mesma dignidade constitucional, o que ocorre precisamente no caso do Brasil.

Ainda que nesses casos (cada vez mais frequentes, como dá conta a evolução constitucional desde o final dos anos 1980) eventuais diferenças em termos de conteúdo e estrutura jurídica entre os direitos das diferentes dimensões não se tornem irrelevantes, o fato é que a própria ordem constitucional vigente optou (por mais que se possa criticar tal opção) em agasalhar tal diversidade de direitos, estabelecendo, ademais disso, um sistema mais ou menos robusto de garantias materiais (institucionais) e procedimentais para viabilizar a sua proteção e mesmo promoção.

É, portanto, o desenho institucional e o regime jurídico dos direitos de uma, duas ou mais dimensões formatado de modo expresso e mesmo implícito por determinada constituição, que sempre expressa um compromisso prévio inclusive do ponto de vista ideológico, que irá presidir o modo como tais direitos se articulam, refletindo também no modo de solução de eventuais tensões e conflitos.

Outrossim, como percebido também por Tushnet, o problema da efetividade é, como tal, comum aos direitos de todas as dimensões, de tal sorte que daí não se deveriam, por si só, extrair conclusões precipitadas sobre uma incompatibilidade e mesmo contradição entre as diversas dimensões, mas sim, privilegiar os instrumentos e níveis de sua realização, inclusive do ponto de vista institucional e funcional, ademais dos aspectos processuais e procedimentais, igualmente objeto da análise de Tushnet.

Isso não significa, importa sublinhar, que para superar a distância entre o discurso normativo e a realidade concreta da efetiva fruição dos diferentes direitos fundamentais, não se devam levar em conta e ponderar as especificidades de cada direito (mesmo no âmbito da mesma dimensão) e a configuração de seus respectivos limites, sempre à luz do regime jurídico que lhes atribuiu o constituinte, ainda que na medida do que decidido pelos Tribunais Constitucionais, o que serve para sustentar a possibilidade e mesmo necessidade de soluções diferenciadas entre ordens jurídico-constitucionais distintas, visto que até mesmo o peso de determinados direitos em relação a outros por vezes também já foi objeto de prévia (ainda que em geral parcial) regulação constitucional, como, apenas em caráter ilustrativo, dá conta o exemplo de Portugal, onde, nos termos da Constituição de 1976, o regime jurídico dos direitos, liberdades e garantias (ou seja, dos direitos da primeira dimensão e das a eles 
equiparadas "liberdades sociais"), é mais qualificado (reforçado) que o dos direitos da segunda e terceira dimensão, o que em parte foi objeto de mitigação pela jurisprudência constitucional (e objeto de acirrada controvérsia doutrinária), sem que contudo fosse afastado o modelo dualista (ainda que relativo) desenhado pelo Constituinte.

O recurso ao teste de proporcionalidade, na condição de técnica para levar a efeito a otimização (acomodação) entre os direitos conflitantes, tal como sugere Tushnet, poderá de fato contribuir para as soluções concretas, em especial na esfera do controle judicial, mas não afastamuito antes pelo contrário, amplia - o leque de críticas que lhe tem sido direcionadas, ainda que em grande parte tais críticas digam respeito mais o modo como se maneja os critérios da proporcionalidade do que ao próprio uso da proporcionalidade como metódica de solução dos conflitos.

Além disso, ainda que possivelmente a questão não tenha escapado a Tushnet (e possa ter sido implicitamente considerada quando este nos fala que há de se aperfeiçoar a técnica da proporcionalidade) não se poderia deixar de fazer referência que na seara dos direitos de caráter positivo, melhor dizendo, da face positiva dos direitos das diferentes dimensões, cada vez mais a doutrina e jurisprudência (basta referir tantos casos julgados pelo STF em matéria de direitos fundamentais, com destaque para os direitos sociais ${ }^{27}$ ) estão investindo na noção da proibição de proteção insuficiente, que carece de acomodação com a clássica compreensão da proporcionalidade, comum aos assim chamados direitos de defesa (direitos negativos), como proibição de excesso de intervenção.

Com isso, por outro lado, a situação se torna ainda mais complexa pois da mesma forma que se amplia o leque de aplicação da proporcionalidade, também se alarga o campo fértil para a sua crítica e mais se desnudam eventuais inconsistências já identificadas quando em causa os convencionais conflitos entre direitos da primeira dimensão.

Ainda nesse contexto, lançando um olhar crítico sobre uma classificação dos direitos fundamentais a partir do critério histórico privilegiado pelo argumento das "dimensões" ou "gerações", Marcelo Cattoni bem observa que na condição de classificação histórica é questionável o quanto tal perspectiva de fato contribui, no plano sistemático (e pragmático, poder-se-á agregar) para um adequado manejo das situações de colisão e concorrência de direitos fundamentais, notadamente em se tratando de direitos de "gerações" diversas, ensejando, como pretende o autor, até mesmo o questionamento da tão

${ }_{27}$ Cf., por exemplo, o caso paradigmático da STF, AgR-STA 175/CE, Tribunal Pleno, Relator Min. Gilmar Mendes, Julgamento em: 17/03/2010.

2 JOURNAL OF INSTITUTIONAL STUDIES 2 (2016) 
difundida - mas possivelmente ainda não suficientemente discutida tese da unidade e interdependência dos direitos fundamentais de todas as dimensões. ${ }^{28}$ Mas tal reflexão, assim como o desenvolvimento dos aspectos atinentes às técnicas de superação dos conflitos entre direitos das três dimensões acessadas por Tushnet, já não será levada a efeito no presente texto, onde nos limitamos a tecer algumas considerações sobre mais um atual e provocador trabalho de um dos mais conhecidos e influentes constitucionalistas da atualidade.

\section{REFERÊNCIAS}

BOBBIO, Norberto. A Era dos Direitos. $8^{\mathrm{a}}$ ed. Trad. Carlos Nelson Coutinho. Rio de Janeiro, RJ: Ed. Campus, 1992.

BONAVIDES, Paulo. A quinta geração de direitos fundamentais. Direitos Fundamentais \& Justiça, Ano 2, no 3, 2008.

BONAVIDES, Paulo. Curso de Direito Constitucional. $7^{a}$ ed. São Paulo, SP: Malheiros, 1999.

BONAVIDES, Paulo. Teoria Constitucional da Democracia Participativa: por um direito constitucional de luta e resistência, por uma nova hermenêutica, por uma repolitização da legitimidade. São Paulo, SP: Malheiros, 2001.

BRANDÃO, Paulo de Tarso. Ações Constitucionais: novos direitos e acesso à justiça. Florianópolis, SC: Habitus, 2001.

${ }^{28}$ Cf. OLIVEIRA, Marcelo Andrade Cattoni de. Teoria Discursiva da Argumentação Jurídica de aplicação e Garantia Processual Jurisdicional dos Direitos Fundamentais. In: Marcelo Andrade Cattoni de Oliveira (Org.). Jurisdição e Hermenêutica Constitucional: no Estado Democrático de Direito. Belo Horizonte, MG: Mandamentos, 2004, p. 192 e ss. (criticando a classificação histórica) e 198 e ss. (discutindo o dogma da interdependência). 
DENNINGER, Erhard. Der Gebändigte Leviathan. Baden-Baden: Nomos Verlagsgesellschaft, 1990.

FACHIN, Zulmar; SILVA, Deise Marcelino da. Acesso à água potável: Direito fundamental de sexta dimensão. Campinas, SP: Brazil Millennium, 2011.

LAFER, Celso. A Reconstrução dos Direitos Humanos: Um Diálogo com o Pensamento de Hannah Arendt. São Paulo, SP: Companhia das Letras, 1988.

OLIVEIRA JÚNIOR, José Alcebíades de. Teoria Jurídica e Novos Direitos. Rio de Janeiro, RJ: Lumen Juris, 2000.

OLIVEIRA, Marcelo Andrade Cattoni de. Teoria Discursiva da Argumentação Jurídica de aplicação e Garantia Processual Jurisdicional dos Direitos Fundamentais. In: Marcelo Andrade Cattoni de Oliveira (Org.). Jurisdição e Hermenêutica Constitucional: no Estado Democrático de Direito. Belo Horizonte, MG: Mandamentos, 2004.

PÉREZ LUÑO, Antonio-Enrique, Las generaciones de derechos Humanos. Revista del Centro de Estudios Constitucionales, n. 10, 1991.

RIEDEL, Eibe. Menschenrechte der dritten Dimension. Europäische Grundrechte Zeitschrift, Vol. 16, 1/2, 1989.

SAMPAIO, José Adércio Leite. Direitos Fundamentais: Retórica e Historicidade. Belo Horizonte, MG: Del Rey, 2004.

SARLET, Ingo Wolfgang. A Eficácia dos Direitos Fundamentais: Uma Teoria Geral dos Direitos Fundamentais na Perspectiva

Constitucional. 10 ${ }^{\mathrm{a}}$ ed. Porto Alegre, RS: Livraria do Advogado, 2009. 
TRINDADE, Antônio Augusto Cançado. Tratado de Direito Internacional dos Direitos Humanos. Vol. I. Porto Alegre, RS: S.A. Fabris, 1997.

TUSHNET, Mark. Notes on Some Aspects of the Taxonomy of

"Generations" of Rights. Revista Estudos Institucionais, Vol. 2, 2, 2016.

WEIS, Carlos. Direitos Humanos Contemporâneos. São Paulo, SP: Malheiros, 1999.

WOLKMER, Antônio Carlos. Introdução aos fundamentos de uma teoria geral dos "novos" direitos. In: Antônio Carlos Wolkmer \& José Rubens Morato Leite (Orgs.). Os “Novos” Direitos no Brasil: Natureza e Perspectivas. Uma visão básica das novas conflituosidades jurídicas. 2ª ed. São Paulo, SP: Editora Saraiva, 2003.

Mark Tushnet e as assim chamadas Dimensões ("Gerações") de Direitos Humanos e Fundamentais Mark Tushnet and the so called Dimensions ("Generations"): Breves Notas of Human and Fundamental Rights: Brief Notes Submetido em: 2016-12-14 